\title{
A INCONSTITUCIONALIDADE DO LIMITE DE DEDUÇÃO DAS DESPESAS EDUCACIONAIS NO IRPF E A TUTELA JURISDICIONAL PARA A CONCRETIZAÇÃO DO DIREITO FUNDAMENTAL À EDUCAÇÃO.
}

\section{Darlan Alves Moulin ${ }^{1}$}

\section{RESUMO}

Trata-se de estudo da inconstitucionalidade do limite a dedução das despesas educacionais da base de cálculo do IRPF. Tem-se por problemática, que esse limite ofende preceitos constitucionais do direito à educação e o conceito de renda, pois essa tributação recai sobre parcela dos rendimentos, essencial a vida digna. Busca-se a possibilidade da declaração de inconstitucionalidade que limita referida dedução, com o objetivo de garantir o Direito à Educação e efetivação da Dignidade Humana. Utilizou-se métodos de revisão bibliográfica e análise da decisão proferida pelo Órgão Especial do TRF $3^{\mathrm{a}}$ Região que garantiu a integral dedução das despesas educacionais.

Palavras-Chave: Educação. Direito Fundamental. Imposto de renda. Limites de dedução. Inconstitucionalidade.

\section{THE UNCONSTITUTIONALITY OF THE DEDUCTION LIMIT OF EDUCATIONAL EXPENSES IN IRPF AND THE JURISDICTIONAL GUARANTEE FOR THE CONCRETIZATION OF FUNDAMENTAL LAW TO EDUCATION.}

\begin{abstract}
It is a study of the unconstitutionality of the limit the deduction of educational expenses from the calculation basis of the Personal Income Tax (IRPF). It is problematic that this limit offends constitutional precepts of the right to education and the concept of income, since this taxation falls on a portion of income, essential to a dignified life. It is sought the possibility of a declaration of unconstitutionality that limits said deduction, with the purpose of guaranteeing the Right to Education and effective Human Dignity. We used methods of bibliographic review and analysis of the decision pronounced by the Special Organ of TRF 3rd Region that guaranteed the full deduction of educational expenses.
\end{abstract}

Keywords: Education. Fundamental Law. Income Tax. Limits of deduction. Unconstitutionality.

\section{INTRODUÇÃO}

\footnotetext{
${ }^{1}$ Mestrando em Direito pelo Centro Universitário Salesiano de São Paulo - UNISAL/ Lorena-SP. Professor de Direito Constitucional, Financeiro e Tributário na Universidade Estácio de Sá- UNESA/RJ.
} 
O presente artigo tem por finalidade analisar a constitucionalidade do limite estabelecido pela Lei Federal $n^{\circ}$ 9.250/95 e suas posteriores alterações no que se refere à dedutibilidade das despesas com educação da base de cálculo do imposto de renda pessoa física (IRPF), tendo em vista que esse limite acaba por ofender diversos preceitos constitucionais que elevaram a educação ao patamar de Direito Social Fundamental, o qual deve ser efetivamente concretizado, tendo em vista que o Brasil é considerado um Estado Democrático e Social de Direito. Além disso, pretende-se verificar como os Tribunais têm tutelado esse direito fundamental.

Inicialmente, será analisada a educação como um direito fundamental de segunda dimensão, tendo em vista que a educação é um direito humano que foi positivado em nosso ordenamento jurídico, razão pela qual deve receber total proteção do Estado, inclusive nas deduções de tais despesas da base de cálculo do IRPF.

Além disso, será realizada uma sucinta análise do imposto de renda, bem como da possibilidade de deduções das despesas educacionais da base de cálculo do referido imposto. Será analisado o conceito de renda e o fato gerador de tal imposto que é o acréscimo patrimonial. Será verificado, ainda, se o atual valor utilizado como limite para as deduções com despesas educacionais pode ser considerado constitucional a luz dos preceitos fundamentais da Constituição Federal.

Nesse sentido, este estudo analisará se o limite estabelecido pela já citada lei federal para as despesas com educação pode ser considerado constitucional pela nova interpretação constitucional ou se tal limitação padece de algum vício de inconstitucionalidade.

Por fim, o presente artigo verificará como tem sido a tutela jurisdicional do direito fundamental à educação quanto à integral dedução das despesas educacionais da base de cálculo do IRPF. Verificará como o STF tem se posicionado quanto aos processos que tem sido levado ao seu conhecimento para apreciação da matéria, seja através de Recurso Extraordinário ou através de Ação Direta de Inconstitucionalidade, bem como a decisão proferida pelo Tribunal Regional Federal da $3^{a}$ Região declarando a inconstitucionalidade do limite de dedução das despesas educacionais da base de cálculo do IRPF, concretizando, assim, o Direito Social Fundamental à Educação.

Na elaboração deste artigo foi utilizado o método de revisão bibliográfica e análise jurisprudencial, especialmente, a decisão proferida pelo Órgão Especial do Tribunal Regional 
Federal da $3^{\text {a }}$ Região que garantiu aos contribuintes, ainda que nos casos concretos levados ao seu julgamento, a integral dedução das despesas educacionais da base de cálculo do IRPF.

\section{A EDUCAÇÃO COMO UM DIREITO FUNDAMENTAL DE SEGUNDA DIMENSÃO}

\subsection{Breve análise dos Direitos Fundamentais}

Inicialmente, cumpre esclarecer a relação existente entre os direitos fundamentais e os direitos humanos. Os direitos fundamentais são os direitos humanos que foram positivados nas Constituições de cada Estado Soberano a fim de serem tutelados no ordenamento jurídico interno, visando à concretização da dignidade humana, bem como a limitação do poder do Estado, enquanto que os direitos humanos são aqueles inerentes à pessoa humana, sem que necessariamente estejam positivados dentro do ordenamento jurídico interno de determinado Estado Soberano. Nesse sentido, Flávio Gonçalves leciona que

[...] a expressão "direitos fundamentais" é que tem um sentido mais restrito, já que se refere apenas aos direitos humanos positivados, enquanto que a locução "direitos humanos" é mais abrangente, abarcando todo e qualquer direito inerente à pessoa humana, positivado ou não. (1997, p. 36).

Assim, pode-se verificar que os Direitos Fundamentais são os Direitos Humanos positivados dentro de determinado ordenamento jurídico. Os Direitos Humanos positivados dentro do ordenamento jurídico de determinado Estado Soberano indicam que os direitos fundamentais são de extrema importância para a concretização da dignidade humana, para o exercício da cidadania e da real democracia, bem como para a limitação do poder do Estado.

Cumpre esclarecer, ainda, que a Constituição de cada Estado é a fonte primária dos Direitos Fundamentais, os quais devem visar à proteção a dignidade humana, garantindo, desta forma, o direito ao mínimo existencial e a não coisificação do ser humano. Corroborando este entendimento, Ingo Sarlet expõe que

Onde não houver respeito pela vida e pela integridade física e moral do ser humano, onde as condições mínimas para uma existência digna não forem asseguradas, onde não houver limitação do poder, enfim, onde a liberdade e autonomia, a igualdade e os direitos fundamentais não forem reconhecidos e minimamente assegurados, não haverá espaço para a dignidade da pessoa humana e esta, por sua vez, poderá não passar de mero objeto de arbítrio e injustiças. (2009, p. 65). 
Vale ressaltar que os direitos fundamentais surgiram com a afirmação do Estado Democrático de Direito no século XVIII e não representam uma ideia engessada ou imutável. Ao contrário, a concepção dos direitos fundamentais se reveste da ideia de continuidade e complementaridade, os quais evoluem com o tempo, junto com o desenvolvimento da civilização.

Inspirado na tríade da revolução francesa: liberdade, igualdade e fraternidade, o jurista Karel Vasak em 1979 desenvolveu a teoria das gerações dos direitos. Sobre o assunto, Piosevan afirma que

De acordo com o referido jurista, a primeira geração dos direitos humanos seria a dos direitos civis e políticos, fundamentados na liberdade (liberté). A segunda geração, por sua vez, seria a dos direitos econômicos, sociais e culturais, baseados na igualdade (égalité). Por fim, a última geração seria a dos direitos de solidariedade, em especial o direito ao desenvolvimento, à paz e ao meio ambiente, coroando a tríade com a fraternidade (fraternité) $(1998$, p. 28).

Desta forma, verifica-se que os direitos fundamentais estão em constante evolução juntamente com a sociedade e que esta evolução visa resguardar a concretização dos direitos fundamentais mínimos para que uma pessoa possa viver com dignidade. Além disso, é importante ressaltar aqui a segunda geração dos direitos fundamentais que é aquela representada pelos direitos sociais, ou seja, por aqueles direitos de cunho prestacional, no qual o Estado deve desenvolver políticas públicas a fim de implementá-los, visando a concretização da dignidade humana.

\subsection{O Direito Fundamental Social à Educação no Ordenamento Jurídico Brasileiro.}

O Direito Social à educação está positivado na Constituição da República Federativa do Brasil de 1988 nos artigos 6, 23, 205, 208, 209, 227, bem como na Lei $n^{\circ}$ 9394/96. A positivação deste direito fez nascer verdadeiros direitos públicos subjetivos do cidadão, o qual pode exigir prestações positivas dos órgãos estatais, os quais tem o dever de concretizar esse direito, vinculando todos os Poderes constituídos. Nesse sentido, o artigo $6^{\circ}$ da Constituição Federal dispõe que

Art. $6^{\circ}$ - São Direitos sociais A EDUCAÇÃO, a saúde, o trabalho, o lazer, a segurança, a previdência social, a proteção à maternidade e à infância social, a proteção à maternidade e à infância, a assistência aos desamparados, na forma desta Constituição. (Grifo nosso). 
Além disso, os artigos 205, caput e 209 da CF/88, que também tratam sobre o direito a educação, dispõem que:

Art. 205. A EDUCAÇÃO, direito de todos E DEVER DO ESTADO e da família, será promovida e incentivada com a colaboração da sociedade, visando ao pleno desenvolvimento da pessoa, seu preparo para o exercício da cidadania e sua qualificação para o trabalho. (Grifo nosso).

Art. 209. O ensino é livre à iniciativa privada, atendidas as seguintes condições: I cumprimento das normas gerais da educação nacional; II - autorização e avaliação de qualidade pelo Poder Público.

Vale ressaltar que, além da positivação deste direito na Constituição Federal de 1988, o direito a educação encontra-se resguardado na Declaração Universal dos Direitos do Homem, a qual em seu artigo XXVI afirma que

Art. XXVI - 1. Toda pessoa tem direito à instrução. A instrução será gratuita, pelo menos nos graus elementares e fundamentais. A instrução técnico-profissional será acessível a todos, bem como a instrução superior, esta baseada no mérito. (ONU, 2017).

O direito à educação deve ser efetivado pelo Estado, o qual tem o dever de atuar de forma positiva e negativa na concretização deste direito. A positivação deste direito faz nascer para o cidadão o direito público subjetivo de exigir do Poder Público certas prestações para usufruir de forma satisfatória de tal direito. Além disso, esse cidadão pode exigir também que o Poder Público não crie dificuldades para o exercício deste direito. Robert Alexy ao lecionar sobre os direitos fundamentais, especialmente os de cunho social, afirmou que

O modelo não determina quais direitos fundamentais sociais o indivíduo tem. (...) Mesmo assim, é possível dar uma resposta geral. Uma posição no âmbito dos direitos a prestações tem que ser vista como definitivamente garantida se (1) o princípio da liberdade fática a exigir de forma premente e se (2) o princípio de separação dos poderes e o princípio democrático bem como (3) os princípios materiais colidentes forem afetados em uma medida relativamente pequena pela garantia constitucional da posição prestacional e pelas decisões do tribunal constitucional que a levarem em consideração. Essas condições são satisfeitas nos casos de direitos sociais mínimos como, por exemplo, o mínimo existencial, a moradia simples, A EDUCAÇÃO FUNDAMENTAL e um patamar mínimo de assistência médica. (2008, p. 512, grifo nosso).

Corroborando este entendimento, Ricardo Lobo Torres leciona que:

O mínimo existencial é de direito subjetivo protegido negativamente contra a intervenção do Estado e, ao mesmo tempo, garantido positivamente pelas prestações estatais. Diz-se, pois, que é direito de status negativus e de status positivus, sendo certo que não raro se converte uma na outra ou se complicam mutuamente a proteção constitucional positiva e negativa. (TORRES, 1999, p. 164). 
Desta forma, verifica-se que a educação é um direito fundamental de segunda dimensão, uma vez que esse direito é indispensável para que a pessoa possa viver com dignidade, uma vez que "o direito social à educação está diretamente vinculado à dignidade da pessoa humana. [...] $\mathrm{O}$ acesso à educação é uma das formas de realização concreta do ideal democrático". (REMÉDIO; COELHO, 2012, p. 31-32).

Além disso, tal direito encontra-se positivado em nossa Constituição Federal, bem como na Declaração Universal dos Direitos do Homem, razão pela qual pode-se verificar que esse direito humano encontra-se positivado no patamar de Direito Fundamental na República Federativa do Brasil, devendo para tanto receber toda a proteção contra as arbitrariedades do poder público, dentre elas contra a tributação indevida, conforme será analisado a seguir.

\section{CONSIDERAÇÕES SOBRE O IMPOSTO DE RENDA E AS DEDUÇÕES COM GASTOS EDUCACIONAIS}

\subsection{Breve análise do Imposto de Renda Pessoa Física}

O imposto de renda é uma espécie de tributo de competência da União Federal, prevista no artigo 153, III, da Constituição Federal de 1988. Tal imposto encontra-se disciplinado no Código Tributário Nacional, em seu artigo 43, incisos I e II, os quais definem as hipóteses em que este imposto irá incidir, quais sejam: a renda e os proventos de qualquer natureza.

Art. 43 - O imposto, de competência da União, sobre renda e proventos de qualquer natureza, tem como fato gerador a aquisição da disponibilidade econômica ou jurídica:

I - de renda, assim entendido o produto do capital, do trabalho ou da combinação de ambos;

II - de proventos de qualquer natureza, assim entendidos os acréscimos patrimoniais não compreendidos no inciso anterior.

Além disso, o contribuinte do imposto de renda pessoa física (IRPF) é definido através do Decreto n ${ }^{\circ} 3.000$, de 1999 como sendo

Art. $2^{\circ}$ As pessoas físicas domiciliadas ou residentes no Brasil, titulares de disponibilidade econômica ou jurídica de renda ou proventos de qualquer natureza, 
inclusive rendimentos e ganhos de capital, são contribuintes do imposto de renda, sem distinção da nacionalidade, sexo, idade, estado civil ou profissão.

Assim, pode-se verificar que os requisitos mínimos do IRPF é ser pessoa física e esta seja residente ou domiciliada no Brasil e possua disponibilidade jurídica ou econômica de rendas ou proventos de qualquer natureza, sendo que a renda líquida seja superior ao limite estabelecido para a faixa de isenção.

Cumpre esclarecer que o conceito de renda possui um núcleo essencial mínimo, o qual pode ser compreendido como sendo o valor que resta ao contribuinte depois que ele realiza todos os pagamentos das despesas que são essenciais para que ele e seus dependentes possam ter uma vida digna. Nesse sentido, Misabel Derzi (1992, p. 19) afirma que "a soma dos rendimentos pessoais (como remunerações de fatores produtivos), por certo lapso de tempo, é que configura a renda."

Nesse sentido, a referida autora, citando Modesto Carvalhosa ensina que

Para fins de tributação, a renda a ser considerada é sempre a pessoal. Representa ganho econômico por certo período de tempo, assim como a idéia de renda nacional. Mas, por ser de pessoas, somente constituirá renda tributável aquele proveniente de capital (ou fonte patrimonial) pertencente à própria pessoa. (DERZI, 1992, p. 19).

Vale ressaltar que não será qualquer renda que será usada como base de cálculo para o imposto de renda pessoa física (IRPF). A renda utilizada será a que traga a ideia de acréscimo, razão pela qual é imperioso que se faça uma distinção entre a renda bruta que é aquela que o contribuinte efetivamente recebe, e a renda líquida, a qual é definida como sendo a renda recebida pelo contribuinte após realizadas todas as deduções legais indispensáveis para que o contribuinte possa viver com um mínimo de dignidade juntamente com seus dependentes.

Nesse sentido, Noé Winkler leciona que

O mínimo de subsistência, excluído do rendimento bruto, para gerar o valor livre objeto da tributação, deve consistir em importância razoável, que compense os impostos indiretos - sobre o consumo que as classes menos favorecidas suportam na aquisição de bens essenciais. O rendimento livre - atendidas essas circunstâncias, é que deve expressar a capacidade contributiva. (WINKLER, 2002, p. 02).

É importante entender que esse mínimo existencial está relacionado com aquelas despesas habituais que as pessoas realizam para concretizarem os direitos básicos que lhes foram garantidos constitucionalmente. Desta forma, pode-se verificar que as despesas com 
educação, saúde e pensão alimentícia podem ser deduzidas da renda bruta do contribuinte, não podendo integrar a base de cálculo do imposto de renda pessoa física (IRPF).

É necessário deixar claro que, se o valor despendido com tais despesas fosse incorporado à base de cálculo do IRPF acabaria por acarretar uma violação ao fato gerador do referido imposto, ou seja, estaria tributando aquilo que não é renda e, desta forma, acabaria por privar os contribuintes de parcela considerável e indispensável, a qual poderia ser utilizada por estes na concretização de direitos sociais básicos necessários para se ter uma vida com um mínimo de dignidade, uma vez que o IRPF acabaria por configurar um efeito confiscatório, o qual não é admitido no ordenamento jurídico brasileiro, tendo em vista o princípio do não confisco.

3.2 A dedução das despesas com educação da base de cálculo do imposto de renda

A dedução de gastos com educação da base de cálculo do imposto de renda pessoa física encontra-se regulamentada através da Lei $n^{\circ}$ 9.250/95, a qual prevê as hipóteses em que tais gastos poderão ser deduzidos.

Com o objetivo de concretizar o direito social à educação, a referida lei possibilitou que as despesas com educação possam ser deduzidas da base de cálculo do imposto de renda pessoa física. Tal dedução será realizada através do método de abatimento, compensando-se aqueles que desembolsaram quantias próprias para pagamento das mensalidades em instituições privadas de ensino, os quais deixaram de sobrecarregar o ensino público no Brasil, possibilitando à Administração Pública uma melhor reorganização dos recursos públicos.

Ocorre que a Lei $n^{\circ}$ 9.250/95 ao tratar das deduções com despesas educacionais acabou por acarretar uma injustiça, tendo em vista que impôs limites a essa dedução. Para melhor compreensão da problemática, faz-se necessário analisar o dispositivo legal que regulamenta a matéria. Nesse sentido, a Lei ${ }^{\circ}$ 9.250/95, em seu artigo $8^{\circ}$ dispõe que

Art. $8^{\circ} \mathrm{A}$ base de cálculo do imposto devido no ano-calendário será a diferença entre as somas:

I - de todos os rendimentos percebidos durante o ano-calendário, exceto os isentos, os não-tributáveis, os tributáveis exclusivamente na fonte e os sujeitos à tributação definitiva; 
II - das deduções relativas: (...)

b) a pagamentos de despesas com instrução do contribuinte e de seus dependentes, efetuados a estabelecimentos de ensino, relativamente à educação infantil, compreendendo as creches e as pré-escolas; ao ensino fundamental; ao ensino médio; à educação superior, compreendendo os cursos de graduação e de pós-graduação (mestrado, doutorado e especialização); e à educação profissional, compreendendo o ensino técnico e o tecnológico, até o limite anual individual de: (...)

10. R\$ 3.561,50 (três mil, quinhentos e sessenta e um reais e cinquenta centavos), a partir do ano-calendário de 2015; (Redação dada pela Lei $\mathrm{n}^{\circ} 13.149$, de 2015) (Grifo nosso).

Verifica-se com o citado dispositivo legal que o legislador acabou por ocasionar uma grande injustiça para os contribuintes, uma vez que impôs limites aos gastos com educação. Analisando as hipóteses de deduções, pode-se verificar que os pagamentos de pensões alimentícias, a contribuição para a previdência privada, bem como as despesas realizadas com saúde do contribuinte e de seus dependentes podem ser integralmente deduzidas da base de cálculo do imposto de renda. ${ }^{2}$

No entanto, as despesas com educação foram limitadas pelo legislador. Com essas despesas, o contribuinte pode obter uma dedução anual individual, a qual pode variar de acordo com o determinado em cada ano-calendário, que para 2016 foi estipulado o limite individual de $\mathrm{R} \$ 3.561,50$ (três mil, quinhentos e sessenta e um reais e cinquenta centavos). ${ }^{3}$

Assim, pode-se verificar que aquele que utilizar um ensino privado para si e seus dependentes somente poderá deduzir da base de cálculo do IRPF o montante fixado pelo legislador. $\mathrm{O}$ valor que ultrapassar o limite fixado em lei será tributado normalmente, uma vez que será considerado como renda para os fins tributários em face da aquisição de disponibilidade econômica.

Ao analisar o disposto no artigo $8^{\circ}$, II, b, da Lei $n^{\circ}$ 9.250/95 pode-se verificar que esta limitação na dedutibilidade das despesas com educação da base de cálculo do IRPF acaba por ocasionar uma inconstitucionalidade, tendo em vista que tal disposição legal não condiz com o espírito de concretização dos direitos fundamentais sociais existentes em nosso Estado Democrático de Direito. Nesse sentido, Leandro Paulsen afirma que

\footnotetext{
${ }^{2}$ Artigo $8^{\circ}$, II, a, e, f, da Lei $n^{\circ} 9250 / 95$.

${ }^{3}$ Artigo $8^{\circ}$, II, b, 10, da Lei $n^{\circ}$ 9250/95 com a redação dada pela Lei $n^{\circ} 13.149$, de 2015.
} 
[...] a tributação, no Estado Democrático de Direito, constitui instrumento da sociedade. É através das receitas tributárias que são viabilizadas a manutenção da estrutura política e administrativa do Estado e as ações do governo. Mas a tributação arbitrária ou excessiva pode por si própria, ter efeitos perversos. (PAULSEN, 2009, p. 13).

Desta forma, a finalidade do tributo no Estado Democrático de Direito deve ser a concretização da Dignidade Humana e dos Direitos Fundamentais, pois

\begin{abstract}
Desta forma, o recolhimento de tributos no Estado Democrático de Direito é instrumento apto a proteger a dignidade humana e os direitos fundamentais já que viabiliza a própria atuação positiva do Estado para concretizar os objetivos constitucionais como redução das desigualdades sociais que é promovida, em geral, pela concretização dos direitos sociais - direitos que em geral, mas não necessariamente, carecem mais de recursos materiais e financeiros. (BOLESINA; GERVASONI, 2016, p. 469-470).
\end{abstract}

Esses direitos sociais fundamentais são tutelados dentro do Estado Democrático de Direito através da proteção do mínimo existencial, ou seja, daquelas condições mínimas para que as pessoas possam viver com dignidade, uma vez que "O Estado Tributário não pode retirar do contribuinte aquilo que como Estado Social, tem de lhe devolver" (TIPKE, 2002, p. $31)$.

Por tais razões, verifica-se que a limitação na dedutibilidade das despesas com educação da base de cálculo do IRPF acaba por ofender os objetivos da própria República Federativa do Brasil, razão pela qual é considerada inconstitucional como será analisado a seguir.

\title{
4. A INCONSTITUCIONALIDADE DO LIMITE DE DEDUÇÃO DO IRPF COM AS DESPESAS EDUCACIONAIS
}

A possibilidade de se deduzir as despesas relacionadas com a educação da base de cálculo do IRPF deve ser no sentido de ser a mais ampla possível (SABBAG, 2009, p. 1013), tendo em vista que a limitação imposta pela legislação padece de flagrante inconstitucionalidade, uma vez que afronta diretamente alguns dispositivos constitucionais, tais como o direito fundamental à educação, os princípios da dignidade humana, da capacidade contributiva, da proporcionalidade e razoabilidade, bem como o conceito de renda. 
De acordo com Hugo de Brito Machado (2009, p. 72), o direito à dedutibilidade de certas despesas da base de cálculo do IRPF não pode ser entendido como um mero incentivo fiscal, uma vez que tal direito é uma das limitações constitucionais ao poder de tributar, já que o IRPF deve incidir apenas sobre a renda do contribuinte e não sobre suas despesas.

Cumpre esclarecer que existe uma grande problemática na relação existente entre as normas constitucionais, que visam garantir os direitos fundamentais, e as normas infraconstitucionais que visam regulamentar tais direitos. (CANOTILHO, 2003, p. 1261).

Desta forma, verifica-se que a lei que regulamenta as deduções das despesas com educação da base de cálculo do IRPF é uma norma infraconstitucional que acaba por restringir o exercício pleno do direito fundamental à educação. Tal restrição somente poderia ser admitida como exceção (SCHIMITT, 2003, p.171).

Nesse sentido, Canotilho (2003, p. 436-440) afirma que as normas constitucionais que consagram os Direitos Sociais exigem que a interpretação das normas infraconstitucionais que regulamentam esses direitos seja conforme a "constituição social econômica e social", servindo como modelo para o controle jurisdicional de tais dispositivos infraconstitucionais restritivos de direitos fundamentais.

Assim, pode-se verificar que há grande violação ao princípio da razoabilidade quanto à dedução das despesas da base de cálculo do IRPF, uma vez que as despesas realizadas com saúde podem ser integralmente deduzidas, enquanto as despesas com educação possuem uma limitação imposta pela norma legal que regulamenta o imposto.

Nessa linha de entendimento, Ingo Sarlet (2014, p. 115) leciona que a Constituição Federal da República Federativa do Brasil de 1988 não estabelece distinção entre os direitos fundamentais nela positivados, não estabelecendo proteção específica para determinado direito fundamental em detrimento de outro.

Com isso, verifica-se grande impedimento ao gozo pleno do direito fundamental à educação, razão pela qual se pode afirmar que o limite estabelecido pela lei em relação às deduções com despesas educacionais padece de vício de inconstitucionalidade, tendo em vista configurar-se verdadeiro confisco e gritante ofensa ao princípio da capacidade contributiva, os quais se encontram previstos nos artigos $145, \S 1^{\circ}$, e 150 , IV, ambos da CRFB/88.

Em relação ao princípio da capacidade contributiva, verifica-se que este está relacionado com possibilidade econômica do contribuinte para pagar os tributos (COELHO, 
2006, p. 51). Assim, de acordo com o referido princípio, cada pessoa deve contribuir, solidariamente, dentro das suas possibilidades, sem que esta contribuição afete as condições para que essa pessoa possa viver de forma digna.

Além disso, o IRPF, baseado neste princípio, estabelece que aquele que tem mais renda, deve contribuir para o Estado, juntamente com a sociedade, sem que isto comprometa a sua subsistência. Ao contrário dos que ganham pouco, os quais são isentos do pagamento do IRPF, uma vez que o próprio Estado reconheceu que todos os rendimentos destas pessoas estão, intimamente, relacionados com suas necessidades básicas, ou seja, com a realização do mínimo existencial. (ALEXANDRE, 2012, p. 95).

Quanto ao tema, Ricardo Lobo Torres (2005, p. 200) afirma que o financiamento do Estado por meio dos tributos deve ser realizado de forma solidária, tendo em vista que "a solidariedade entre os cidadãos deve fazer com que a carga tributária recaia sobre os mais ricos, aliviando-se a incidência sobre os mais pobres e dela dispensando os que estão abaixo do nível mínimo de sobrevivência".

Corroborando este entendimento, Casalta Nabais (1998, p. 541) afirma que "o mínimo de existência familiar integra o rendimento indisponível, necessário para assegurar a pais e filhos os pressupostos mínimos de sua dignidade, e, por isso, deve ser excluído da tributação."

Nesse sentido, é importante verificar o entendimento abaixo quanto ao princípio da capacidade contributiva, uma vez que

\footnotetext{
Não pode ser deixado de lado, ainda, o fato de que o princípio da capacidade contributiva se apresenta como um direito fundamental individual do contribuinte em relação aos impostos. Isso significa que o contribuinte tem direito individual de ter suas condições econômicas respeitadas para que não seja atingido seu piso mínimo vital, ou seja, a tributação via impostos não pode impedir a realização dos direitos sociais mínimos para que o cidadão/contribuinte viva com dignidade. (MENEZES; PINTO, 2012. p. 216).
}

Desta forma, verifica-se que o limite de deduções com as despesas educacionais da base de cálculo do imposto de renda pessoa física (IRPF) padece de vício de inconstitucionalidade, tendo em vista as diversas violações a preceitos fundamentais, os quais visam assegurar que o Direito Fundamental Social à Educação seja efetivamente concretizado; resguardando, desta forma, a dignidade da pessoa humana. 
Nesse sentido, verifica-se que a tributação deve ser realizada para a concretização da dignidade humana e dos direitos fundamentais.

\begin{abstract}
Portanto, salienta-se que e em um Estado Democrático de Direito, como é o caso do Brasil, fundamentado e vinculado à dignidade humana também por força constitucional e de modo expresso, o Estado não possui fim em si mesmo, mas sim, existe em função da pessoa humana, sendo imperioso e imprescindível que todas as suas atividades sejam direcionadas ao respeito, à proteção e à promoção da dignidade humana. Seguindo esta lógica, a tributação não deve ser destinada para a satisfação de interesses pessoais ou quaisquer outros que não estejam em harmonia com à dignidade humana e os direitos fundamentais.(BOLESINA; GERVASONI, 2016, p. 470).
\end{abstract}

Assim, faz-se necessário que o Poder Judiciário se manifeste a fim de assegurar aos contribuintes o exercício deste direito, declarando a inconstitucionalidade do dispositivo legal que estabelece um teto individual para as deduções com as despesas educacionais da base de cálculo do IRPF, garantindo-se, assim, o pleno exercício deste direito fundamental.

\title{
5. A DECLARAÇÃO INCIDENTAL DE INCONSTITUCIONALIDADE PELO TRIBUNAL FEDERAL DA $3^{\text {a }}$ REGIÃO E A CONCRETIZAÇÃO DO DIRIETO FUNDAMENTAL À EDUCAÇÃO
}

Como visto anteriormente, o direito fundamental à educação é um direito público subjetivo que legitima o cidadão a exigir do Estado prestações positivas a fim de concretizar esse direito. Desta forma, verifica-se que as deduções integrais das despesas educacionais da base de cálculo do IRPF não se tratam de mera liberalidade do Estado, mas sim de verdadeiro direito público subjetivo do cidadão - contribuinte, tendo em vista que a tributação sobre tais despesas acabam por restringir a capacidade contributiva dos contribuintes, bem como ofendendo o conceito constitucional de renda, razões pelas quais entende-se que esse teto é inconstitucional.

Nesse sentido, o Tribunal Regional Federal da $3^{a}$ Região, por meio de seu órgão especial, declarou a inconstitucionalidade do limite de deduções com despesas educacionais contido no artigo $8^{\circ}$, II, “b”, da Lei $n^{\circ} 9.250 / 95$, cujo teor do julgado segue transcrito

CONSTITUCIONAL. TRIBUTÁRIO. IMPOSTO DE RENDA. PESSOA FÍSICA. LIMITES À DEDUÇÃO DAS DESPESAS COM INSTRUÇÃO. ARGUIÇÃO DE INCONSTITUCIONALIDADE. ART. 8', II, "B", DA LEI No 9.250/95. EDUCAÇÃO. DIREITO SOCIAL FUNDAMENTAL. DEVER 
JURÍDICO DO ESTADO DE PROMOVÊ-LA E PRESTÁ-LA. DIREITO PÚBLICO SUBJETIVO. NÃO TRIBUTAÇÃO DAS VERBAS DESPENDIDAS COM EDUCAÇÃO. MEDIDA CONCRETIZADORA DE DIRETRIZ PRIMORDIAL DELINEADA PELO CONSTITUINTE ORIGINÁRIO. A INCIDÊNCIA DO IMPOSTO SOBRE GASTOS COM EDUCAÇÃO VULNERA O CONCEITO CONSTITUCIONAL DE RENDA E O PRINCÍPIO DA CAPACIDADE CONTRIBUTIVA.

1. Arguição de inconstitucionalidade suscitada pela e. Sexta Turma desta Corte em sede de apelação em mandado de segurança impetrado com a finalidade de garantir o direito à dedução integral dos gastos com educação na Declaração de Ajuste Anual do Imposto de Renda Pessoa Física de 2002, ano-base 2001.

2. Possibilidade de submissão da quaestio juris a este colegiado, ante a inexistência de pronunciamento do Plenário do STF, tampouco do Pleno ou do Órgão Especial desta Corte, acerca da questão.

3. O reconhecimento da inconstitucionalidade da norma afastando sua aplicabilidade não configura por parte do Poder Judiciário atuação como legislador positivo. Necessidade de o Judiciário - no exercício de sua típica função, qual seja, averiguar a conformidade do dispositivo impugnado com a ordem constitucional vigente manifestar-se sobre a compatibilidade da norma impugnada com os direitos fundamentais constitucionalmente assegurados. Compete também ao poder Judiciário verificar os limites de atuação do Poder Legislativo no tocante ao exercício de competências tributárias impositivas.

4. A CF confere especial destaque a esse direito social fundamental, prescrevendo o dever jurídico do Estado de prestá-la e alçando-a à categoria de direito público subjetivo.

5. A educação constitui elemento imprescindível ao pleno desenvolvimento da pessoa, ao exercício da cidadania e à livre determinação do indivíduo, estando em estreita relação com os primados basilares da República Federativa e do Estado Democrático de Direito, sobretudo com o princípio da dignidade da pessoa humana. Atua como verdadeiro pressuposto para a concreção de outros direitos fundamentais.

6. A imposição de limites ao abatimento das quantias gastas pelos contribuintes com educação resulta na incidência de tributos sobre despesas de natureza essencial à sobrevivência do indivíduo, a teor do art. $7^{\circ}, \mathrm{IV}$, da CF, e obstaculiza o exercício desse direito.

7. Na medida em que o Estado não arca com seu dever de disponibilizar ensino público gratuito a toda população, mediante a implementação de condições materiais e de prestações positivas que assegurem a efetiva fruição desse direito, deve, ao menos, fomentar e facilitar o acesso à educação, abstendo-se de agredir, por meio da tributação, a esfera jurídico patrimonial dos cidadãos na parte empenhada para efetivar e concretizar o direito fundamental à educação.

8. A incidência do imposto de renda sobre despesas com educação vulnera o conceito constitucional de renda, bem como o princípio da capacidade contributiva, expressamente previsto no texto constitucional.

9. A desoneração tributária das verbas despendidas com instrução configura medida concretizadora de objetivo primordial traçado pela Carta Cidadã, a qual erigiu a 
educação como um dos valores fundamentais e basilares da República Federativa do Brasil.

10. Arguição julgada procedente para declarar a inconstitucionalidade da expressão "até o limite anual individual de $\mathrm{R} \$ 1.700,00$ (um mil e setecentos reais)" contida no art. $8^{\circ}$, II, "b", da Lei n ${ }^{\circ}$ 9.250/95.

\section{ACÓRDÃo}

Vistos e relatados estes autos em que são partes as acima indicadas, decide o Egrégio Órgão Especial do Tribunal Regional Federal da $3^{\mathrm{a}}$ Região, por maioria, julgar procedente a arguição de inconstitucionalidade para declarar a inconstitucionalidade da expressão "até o limite anual individual de $\mathrm{R} \$ 1.700,00$ (um mil e setecentos reais)" contida no art. 8, II, "b", da Lei $\mathrm{n}^{\circ}$ 9.250/95, devendo os autos retornarem à Turma para o prosseguimento do julgamento da apelação, nos termos do relatório e voto que ficam fazendo parte integrante do presente julgado

Com o retorno dos autos à Sexta Turma do TRF da $3^{\text {a }}$ Região após a decisão reconhecendo a inconstitucionalidade incidental da referida expressão quanto ao limite das deduções com as despesas de educação, os membros da Sexta Turma decidiram nos termos da ementa do acórdão que segue:

TRIBUTÁRIO. MANDADO DE SEGURANÇA. IMPOSTO DE RENDA PESSOA FÍSICA. LIMITAÇÕES ÀS DEDUÇÕES COM DESPESAS DE INSTRUÇÃO. ART. 8', II, ALÍNEA "B", DA LEI 9.250/95. ARGUIÇÃO DE INCONSTITUCIONALIDADE ACOLHIDA PELO ÓRGÃO ESPECIAL DO TRIBUNAL.

1. O Órgão Especial desta Corte acolheu argüição para declarar a inconstitucionalidade da expressão até o limite anual individual de $\mathrm{R} \$ 1.700,00$ (um mil e setecentos reais), contida no art. $8^{\circ}$, II, alínea "b", da Lei 9.250/95 (TRF $3^{\mathrm{a}}$ Região, Órgão Especial, Argüição de Inconstitucionalidade 000506786.2002.4.03.6100/SP, Rel. Des. Fed. Mairan Maia, DE 11.05.2012).

2. A questão não comporta maiores discussões na medida em que a referida decisão vincula os órgãos fracionários deste Tribunal, nos termos do art. 176 do Regimento Interno, razão pela qual deve ser mantida a sentença que concedeu a ordem nesse particular.

7. Apelação provida.

\section{ACÓRDÃO}

Vistos e relatados estes autos em que são partes as acima indicadas, decide a Egrégia Sexta Turma do Tribunal Regional Federal da $3^{\text {a }}$ Região, por unanimidade, dar provimento à apelação, nos termos do relatório e voto que ficam fazendo parte integrante do presente julgado.

Desta forma, verifica-se que a Sexta Turma, seguindo a decisão do Órgão Especial do Tribunal Regional Federal da $3^{\text {a }}$ Região deu provimento, por unanimidade, a apelação 
interposta, reconhecendo o direito do impetrante à dedução integral das despesas com educação.

Cumpre esclarecer que a União Federal interpôs Recurso Extraordinário, o qual foi admitido em 18/05/2016, tendo sido remetido ao STF. Este Recurso Extraordinário foi distribuído sob o $\mathrm{n}^{\circ}$ 980.602, tendo sido designada a Ministra Rosa Weber para relatá-lo.

A Ministra Rosa Weber, relatora do recurso, por decisão monocrática publicada no dia 23/08/2016 negou provimento ao recurso nos seguintes termos

\footnotetext{
Nesse sentir, não merece seguimento o recurso extraordinário, consoante também se denota dos fundamentos da decisão que desafiou o recurso, aos quais me reporto e cuja detida análise conduz à conclusão pela ausência de ofensa a preceito da Constituição da República. Nego seguimento (art. 21, § 1º do RISTF). Publique-se.
}

Contra esta decisão foi interposto agravo regimental em 31/08/2016 estando os autos pendentes de julgamento pelo plenário do Supremo Tribunal Federal. A declaração de inconstitucionalidade feita pelo Tribunal Regional Federal da $3^{\text {a }}$ Região nos autos do incidente de arguição de inconstitucionalidade visou concretizar o Direito Social à Educação no Estado Democrático de Direito a fim de garantir a Dignidade da Pessoa Humana.

Cumpre esclarecer que tramita no Supremo Tribunal Federal a ação direta de inconstitucionalidade $n^{\circ} 4927$ que foi ajuizada pelo Conselho Superior da Ordem dos Advogados do Brasil em 25/03/2013, na qual visa a declaração, via controle concentrado e abstrato, da inconstitucionalidade do teto estabelecido pela lei das despesas com educação.

Nesta ação, foi requerida a suspensão dos efeitos da referida lei que impõe a dedutibilidade dos gastos com educação, mas a relatora do caso Ministra Rosa Weber, entendeu ser a matéria relevante para a ordem social e segurança jurídica, razão pela qual determinou que a ação tramitasse de acordo com o artigo 12 da Lei no 9868/99. Vale ressaltar que os autos encontram-se conclusos com a relatora desde 08/05/2017 a fim de que possa se manifestar sobre o caso.

Importante salientar que é necessário que o STF se manifeste sobre o caso em análise, a fim de que seja uniformizado o entendimento em todos os Tribunais do país sobre a matéria, tendo em vista que o limite com as deduções das despesas com educação da base de cálculo do IRPF acaba por dificultar a concretização do Direito Fundamental à Educação para os contribuintes. 
Além disso, verifica-se que tal limite acaba por fazer um tratamento diferenciado entre direitos fundamentais resguardados pela Constituição Federal. Assim, é necessário que haja um tratamento isonômico entre o direito à educação e os direitos à saúde e alimentação (pensão alimentícia), tendo em vista que estes direitos podem ser integralmente deduzidos da base de cálculo do IRPF.

Desta forma, é necessário que o STF se manifeste de forma a possibilitar a dedução integral das despesas educacionais, declarando a inconstitucionalidade, de forma concentrada e abstrata, do teto da dedutibilidade de tais gastos, visando à concretização do Direito Social Fundamental à Educação e da Dignidade da Pessoa Humana.

\section{CONSIDERAÇÕES FINAIS}

Por meio do presente estudo, pôde-se verificar que o limite de deduções da base de cálculo do IRPF com as despesas educacionais, previstas no artigo $8^{\circ}$, II, "b", da Lei $\mathrm{n}^{\mathrm{o}}$ 9.250/95 padece de vício de inconstitucionalidade, tendo em vista que tal limitação acaba por ofender diversos preceitos constitucionais.

É importante salientar que existe a ADIN 4927 em trâmite junto ao Supremo Tribunal Federal (STF), na qual pretende obter a tutela jurisdicional a fim de que seja declarada, de forma concentrada e abstrata, a inconstitucionalidade do referido dispositivo legal.

Entretanto, vale ressaltar que, o STF não se posicionou de forma definitiva sobre o assunto, razão pela qual os Tribunais têm decidido a questão, nos casos concretos que lhes são apresentados para julgamento, sobre a constitucionalidade ou não do dispositivo legal que impõe limites à dedutibilidade das despesas educacionais da base de cálculo do IRPF.

Nesse sentido, o Órgão Especial do Tribunal Regional Federal da $3^{\mathrm{a}}$ Região entendeu, no julgamento de um incidente de argüição de inconstitucionalidade, que o limite de dedução com gastos relacionados com educação era inconstitucional, razão pela afastou a incidência da referida norma naquele caso concreto, permitindo a dedução integral das despesas com educação, bem como firmou entendimento a ser observado neste Tribunal quando do julgamento de feitos que versem sobre a inconstitucionalidade de tais deduções da base de cálculo do IRPF. 
No julgamento do citado incidente de arguição de inconstitucionalidade, o TRF da $3^{\mathrm{a}}$ Região entendeu que o limite de deduções estabelecido pela lei acabava por vulnerar o conceito constitucional de renda, bem como o princípio da capacidade contributiva, uma vez que o valor gasto com educação não pode ser considerado renda para fins de tributação.

A educação é um Direito Social Fundamental e, como tal, deve ser protegido pela Constituição, recebendo a devida tutela jurisdicional sempre que houver qualquer lesão ou ameaça de lesão a esse direito.

O limite estabelecido pela lei para a dedução dos gastos com educação acaba fazendo com que o IRPF incida sobre valores utilizados para garantir a subsistência dos indivíduos. Desta forma, o Estado acaba por tributar aquilo que não pode ser considerado renda e, consequentemente, ofende diretamente o mínimo existencial e a capacidade contributiva dos contribuintes, constituindo a tributação do IRPF sobre a parcela utilizada para essas despesas um verdadeiro confisco.

Neste artigo, foi analisada a questão da educação como direito fundamental que deve ser protegido, bem como o que pode ser definido como renda para fins de tributação. Verificou-se, ainda, a tutela jurisdicional que pode ser realizada a fim de resguardar a concretização de tal direito.

Por fim, foi verificado que está nas mãos dos ministros do STF o poder de decisão sobre essa importante questão. Esperamos que os nobres ministros se posicionem, o mais breve possível, para tutelar o Direito Fundamental à Educação, possibilitando a dedução integral das despesas educacionais da base de cálculo do IRPF para que todos os contribuintes desse imposto possam exercitar, de forma plena, esse direito constitucionalmente garantido.

Entretanto, enquanto o STF não tem uma decisão final sobre a questão, compete aos Tribunais Regionais Federais e aos Tribunais dos estados a tutela desse direito fundamental, por via incidental e concreta. Nesse sentido, já foi declarada a inconstitucionalidade do referido limite pelo TRF da $3^{\text {a }}$ Região, o qual possibilitou a dedução integral das despesas com educação da base de cálculo do IRPF, garantindo, assim, a efetividade do Direito Social Fundamental à Educação e a concretização da Dignidade da Pessoa Humana.

\section{REFERÊNCIAS}


ALEXANDRE, Ricardo. Direito tributário esquematizado. 6. ed. Rio de Janeiro: Forense; São Paulo: Editora Método, 2012.

ALEXY, Robert. Teoria dos direitos fundamentais. São Paulo: Malheiros, 2008.

BRASIL. Constituição (1988). Constituição da República Federativa do Brasil de 1988. Disponível em: http://www.planalto.gov.br/ccivil_03/Constituicao/Constituiçao.htm>. Acesso em: 01 maio 2017.

Lei $\mathbf{n}^{0}$ 5.172, de 25 de outubro de 1966. Dispõe sobre o Sistema Tributário Nacional e institui normas gerais de direito tributário aplicáveis à União, Estados e Municípios. Disponível em: <http://www.planalto.gov.br/ccivil_03/Leis/L5172.htm>. Acesso em: 01 maio 2017.

Lei $\mathbf{n}^{0}$ 9.250, de 26 de dezembro de 1995. Altera a legislação do imposto de renda das pessoas físicas e dá outras providências. Diário Oficial da União, Brasília, DF, 27 dez 1995.

Supremo Tribunal Federal. STF - RExt. n 980.602 - SP, Rel. Min. Rosa Weber, DJ de 23/08/2016.

Tribunal Regional Federal - $3^{\mathrm{a}}$ Região. TRF $-3^{\mathrm{a}}$ R., Arguição de Inconstitucionalidade Cível $n^{\circ}$ 000506786.2002.4.03.6100/SP, Rel. Des. Fed. Mairan Maia, DJ de 14/02/2012.

BOLESINA, Iuri; GERVASONI, Tamiris Alessandra. A dupla face do mínimo existencial no estado democrático de direito à luz das questões tributárias na concretização dos direitos sociais. Direito e Paz. Lorena, Ano XVIII, n. 35, p. 463-496, 2. sem. 2016.

CANOTILHO, José Joaquim Gomes. Direito Constitucional e Teoria da Constituição. 7 ed. Coimbra: Edições Almedina, 2003.

COELHO, Sacha Calmon Navarro. Comentários à Constituição de 1988. Sistema Tributário. 10. ed. Rio de Janeiro: Forense, 2006.

DERZI, Misabel de Abreu Machado. Os conceitos de renda e patrimônio: efeitos da correção monetária insuficiente no imposto de renda. Belo Horizonte: Del Rey, 1992.

GONÇALVES, Flávio José Moreira. Notas para Caracterização Epistemológica da Teoria dos Direitos Fundamentais. In: GUERRA FILHO, Willis Santiago et al. (Coords.). Dos Direitos Humanos aos Direitos Fundamentais. Porto Alegre: Livraria do Advogado, 1997.

MACHADO, Hugo de Brito. Gastos com educação e imposto de renda. Revista Dialética de Direito Tributário. São Paulo: Dialética, n 165, jun.2009. 
MENEZES, Milena Zampieri Sellmann de; PINTO, Keziah Alessandra Vianna Silva. Uma releitura do princípio da capacidade contributiva à luz do neoconstitucionalismo. Direito e Paz. Lorena, Ano XIV, n. 26, p. 193-225, 1. sem. 2012.

NABAIS, José Casalta. O dever fundamental de pagar impostos. Coimbra: Almedina, 1998.

ONU, Declaração Universal dos Direitos Humanos. Adotada e proclamada pela resolução 217 A (III) da Assembléia Geral das Nações Unidas em 10 de dezembro de 1948. Disponível em:< http://unesdoc.unesco.org/images/0013/001394/139423por.pdf > Acesso em: 12 maio 2017.

PAULSEN, Leandro. Direito Tributário, Constituição e Código Tributário Nacional à Luz da Doutrina e da Jurisprudência. 11. ed. Porto Alegre: Livraria do Advogado, 2009.

PIOVESAN, Flávia. Temas de Direitos Humanos. São Paulo: Max Limonad, 1998.

REMÉDIO, José Antônio; COELHO, Rodrigo Batista. A concretização dos direitos sociais como imperativo da igualdade material: políticas públicas educacionais e tutela coletiva. Direito e Paz. Lorena, Ano XIV, n. 26, p. 09-40, 1. sem. 2012.

SABBAG, Eduardo. Manual de direito tributário. São Paulo: Saraiva, 2009.

SARLET, Ingo Wolfgang. A eficácia dos direitos fundamentais. 12. ed. Porto Alegre: Livraria do Advogado, 2014.

Dignidade da pessoa humana na Constituição Federal de 1988. 7. ed. rev. atual. Porto Alegre: Livraria do Advogado, 2009.

SCHIMITT, Carl. Teoría de La Constitución. Madrid: Alianza Editorial SA, 2003.

TIPKE, Klaus; YAMASHITA, Douglas. Justiça fiscal e princípio da capacidade contributiva. São Paulo: Malheiros, 2002.

TORRES, Ricardo Lobo. Tratado de direito constitucional financeiro e tributário - os direitos humanos e a tributação. Rio de Janeiro: Renovar, 1999.

- Existe um princípio estrutural da solidariedade? In: GRECO, Marco Aurélio; GODOI, Marciano Seabra. Solidariedade Social e Tributação. São Paulo: Dialética, 2005. cap. 9, p. 198-207.

WINKLER, Noé. Imposto de renda. Rio de Janeiro: Forense, 2002. 